\title{
The Faculty of Medicine of the University of São Paulo (FMUSP) Internationalization Strategy
}

\author{
Talita de Almeida
}

\section{INTRODUCTION}

$\mathrm{W}$

ell established as one of the most prestigious public universities in Brazil, the University of São Paulo (USP) was in 2015, ranked first in the Latin American rankings, $9^{\text {th }}$ in the BRICS ranking and $132^{\text {nd }}$ in the QS World University Rankings 2014/15. With a large community of around 90,000 students, the University of São Paulo is located in São Paulo, Brazil's most populous city, and has campi placed in seven towns spread throughout the state of São Paulo.

The Faculty of Medicine of the University of São Paulo (FMUSP) is proud to make part of USP with a significant history as an internationally focused Faculty. Since 2008, FMUSP has been thinking about strategies, which set out how to build on a strong international tradition and reputation to ensure that we are best positioned in Latin America to contribute and thrive in the years ahead. In 2015, FMUSP featured in the top 100 Faculties according to Times Higher Education, we want more!

\section{Our current International Strengths}

Under the joint leadership of our Dean, Prof. Jose Otavio Costa Auler Jr and the International Committee, especially our International Executive Director, Prof. Eduardo Krieger, FMUSP increased, in the last 5 years, its international strategies and actions around the world.

We are currently performing hardy regarding Medical Students mobility. We have succeeded in attracting 55 international students from 24 reputable institutions, such as Harvard Medical School, University of Michigan, Princeton University and Yale University, to our first edition of The Winter Schools. Students came from 18 different countries for designed comprehensive two-week courses on five different topics: Neglected tropical diseases, Principles and cancer control programs, Practical aspects of modern cardiology, Disease prevention and vulnerability reduction and Radio-pathological interactions in the autopsy room. All of them addressing students from various backgrounds, from college students to post-doc fellows. During these two-week activities, FMUSP was home to international students from around the world as well as students from other Brazilian Institutions. With the option to live in University residence halls, students had the chance to truly immerse themselves in the FMUSP "winter" experience.

Additionally, our Faculty receives, every year, an average of 80 International Students willing to undertake one of our practical clerkships. As it shows below, they come mostly from Colombia, Portugal, US and Germany.

International Office Coordinator, FMUSP.

Address: Av. Dr. Arnaldo, 455 Main Building - Room 1345. São Paulo, SP, Brazil. Email: talita.almeida@fm.usp.br 
By encouraging international students to apply for admission, we strongly believe that international students offer to our Professors, students and staff the opportunity to learn more about the world.
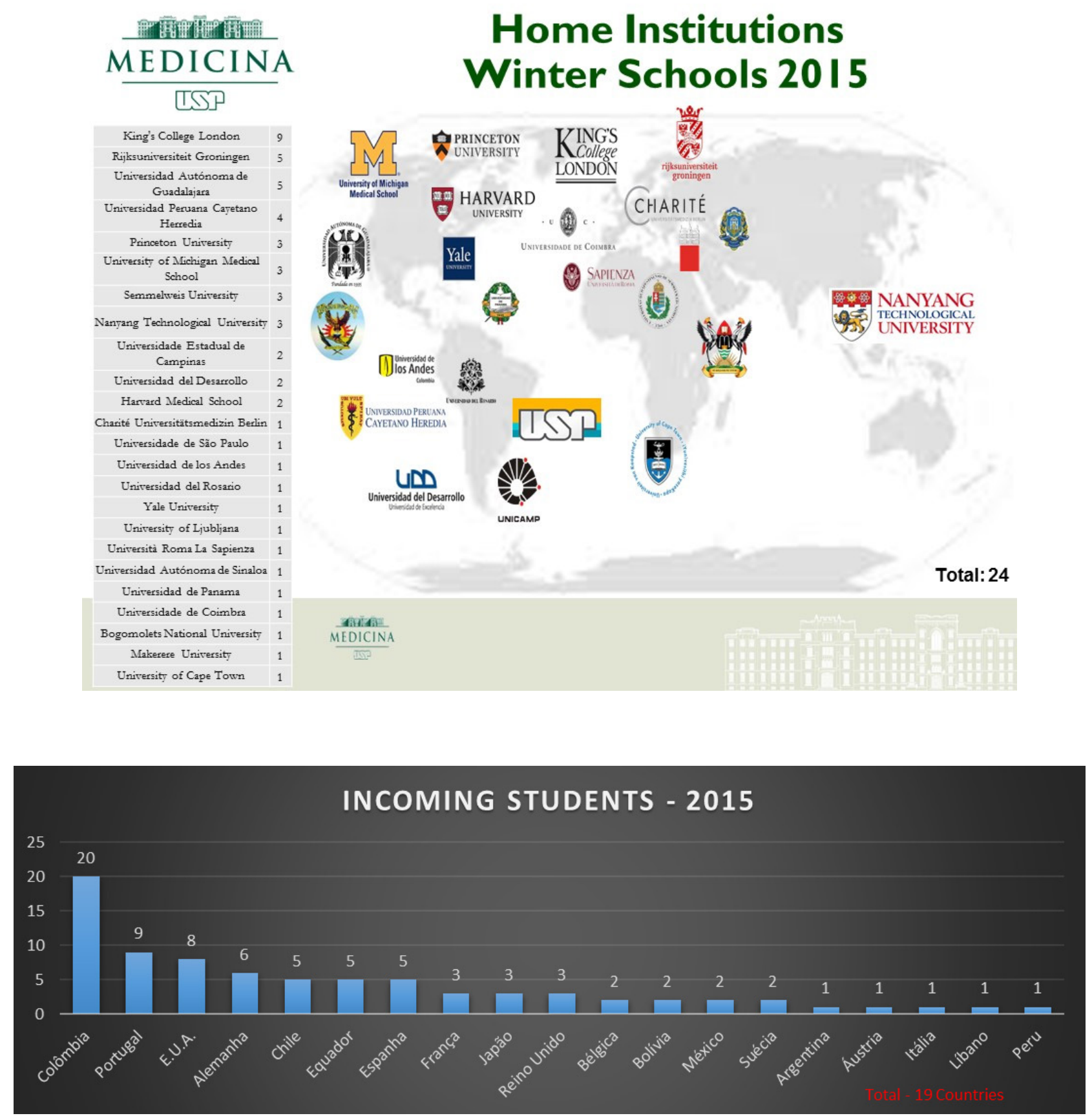

In partnership with 39 institutions worldwide, we also participate in exchange and mobility schemes that offer students, professors and researchers a challenging and exciting international experience, providing them with new perspectives and an understanding of different cultures. In 2015, 51 FMUSP Medical Students went for an exchange experience, either practical clerkship or research.
Thirty nine percent of them chose an academic partner in the US. The interest for international exchange programs has been increasing through study opportunities that exist under University-to-University agreement, a key strategy for the success of discipline revalidation, one of the biggest challenges at FMUSP. 


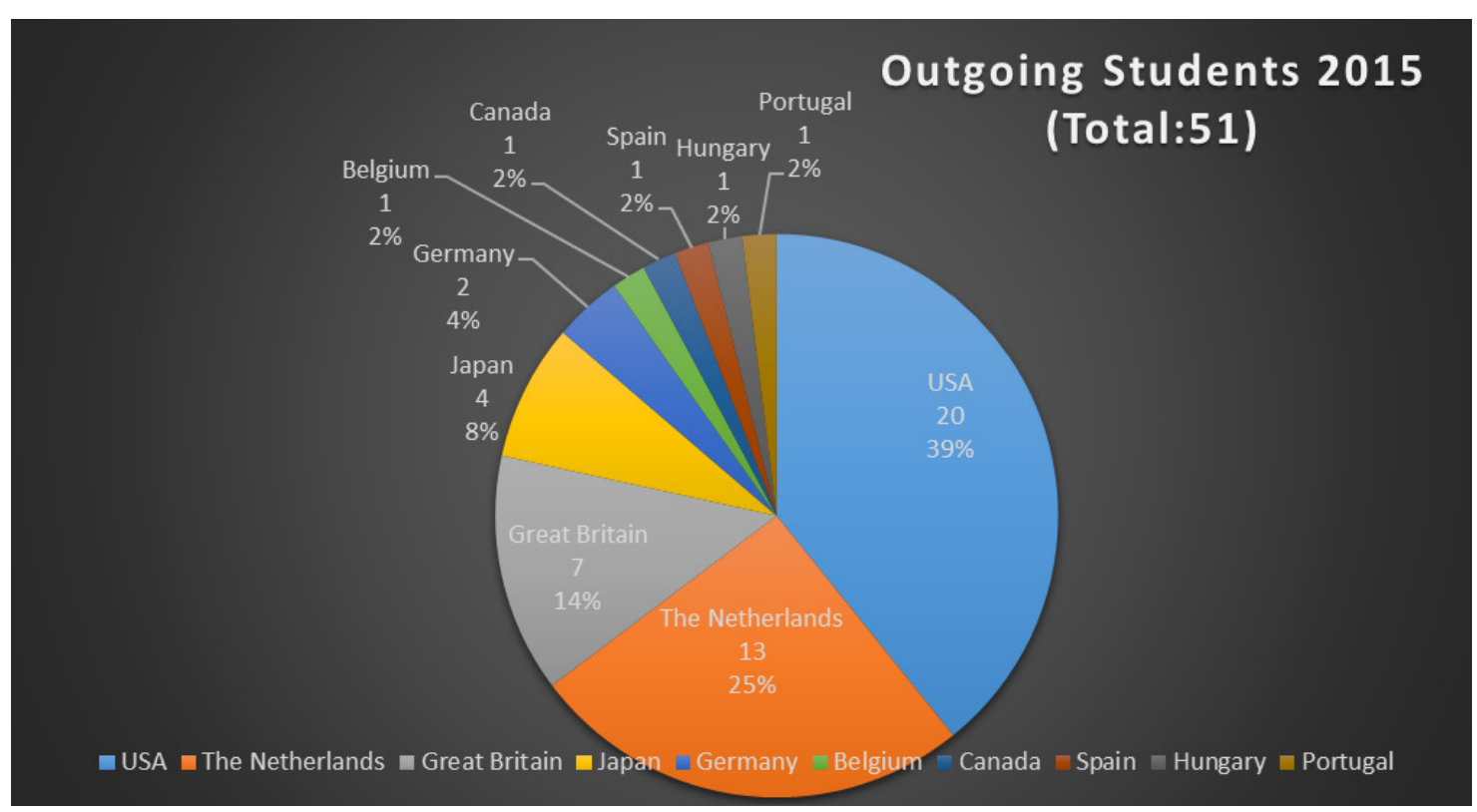

Besides those 39 academic partners, we have developed a range of strategic partnerships with overseas institutions, in particular with US and Canada where we have extended our links with academic institutions such as the University of Michigan and the University of Toronto. A successful example of the implementation of a strategic partnership was the participation of the University of Toronto on our undergraduate medical education curriculum reform and program. The University of Toronto team, led by the expertise of Prof. Sarita Verma, traveled to Brazil for two site visits last year. They provided guidance on the successful implementation of our ongoing reformed undergraduate curriculum and helped us to:

1. Perform a follow up assessment to provide guidance and support during the University of São Paulo's transition to a new undergraduate medical education curriculum and program;

2. Conduct a needs assessment of wellness programs for students, residents and faculty and provide a consultation on the set up, infrastructure and business plan for an office of wellness; and,

3. Conduct faculty development workshops to provide instruction in teaching, evaluation and leadership.

The University of Michigan is another example of mutual partnership. Faculty members from its Medical School have been collaborating with partners at FMUSP for several years. At least seven clinical, educational, and/or research projects are currently underway between the University of Michigan and FMUSP. Many of these professors and researches participated in the first UM-Brazil Platform Symposium, which took place in Ann Arbor in November 2014. We are now, preparing a new symposium at FMUSP this year.

FMUSP also receives an average of 30 international delegations and 10 Visiting Professors per year; in 2015, we had 8 delegations from US and visiting professors from Canada, Germany, US, England and Argentine among others.

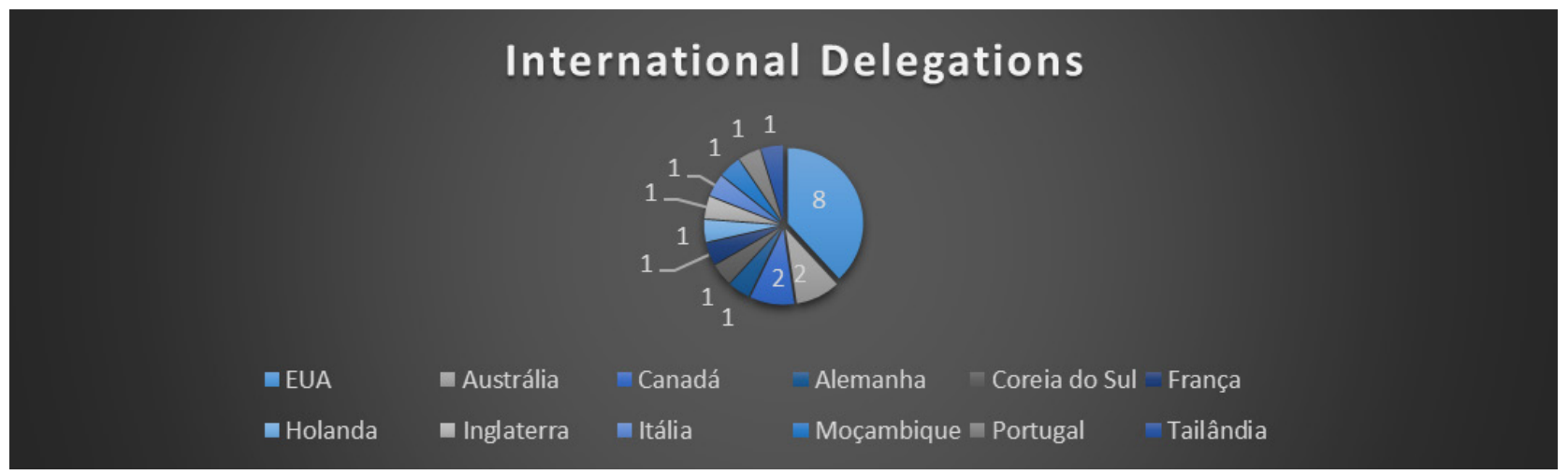




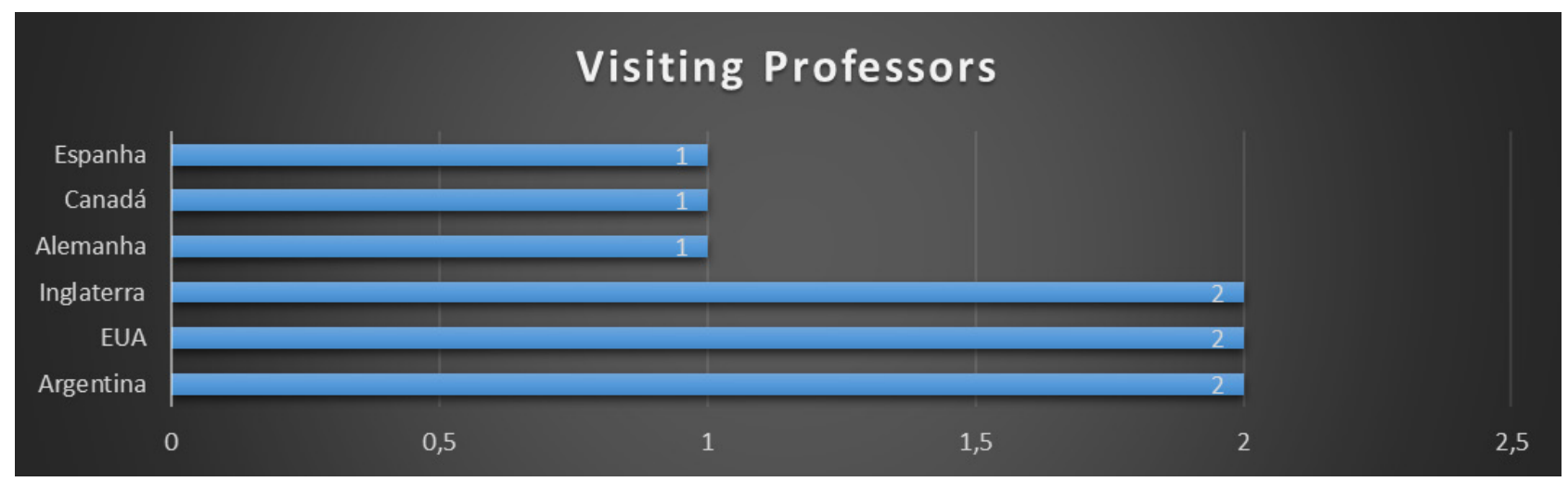

Currently, we engage in two international groupings of Universities, "The Association of Academic Health Centers (AAHC)" and the "M8 Alliance of Academic Health Centers, Universities and National Academies" in order to promote internationalization, academic collaboration, excellence in learning and research, and service to society.

"The M8 Alliance of Academic Health Centers, Universities and National Academies" is a collaborative network of academic institutions known for its educational and research excellence. It is important to highlight that the M8 Alliance - World Health Summit (WHS) happens once a year, in October, in Berlin and it has grown into the world's most prominent forum for addressing global health issues. It brings together key leaders from academia, politics, civil society, and the private sector to address the most pressing health-related challenges on the planet. Also held annually in April, the WHS Regional Meeting is organized by the WHS Co-President of each respective year. The Regional Meetings focus on local issues and solutions and topics and outcomes continues to be discussed at the World Health Summit in Berlin. FMUSP has been active since 2011, and in 2014, we coordinated, for the first time in Latin America, a Regional Meeting. With more than one thousand participants from 27 Countries, the WHS Regional Meeting Latin America - São Paulo focused on the health challenges affecting Latin American countries in particular. At the three-day summit's close, a call for immediate action was released, demanding governments and responsible institutions to act to counter the significant socio-demographic and epidemiological changes in developing countries and their effects on health. Apart from that, we are already one of the M8 Alliance members working on Medical Education and programing a common "Medical curriculum" in Global Health, which can become a distinguishing feature of the M8 Alliance, and a tangible educational product. This curriculum would focus on educational outcomes for the young doctors. It is important to highlight that the M8 Alliance is concerned about the development of new and productive initiatives and interested in setting the stage for leadership in health development initiatives. For that reason, the M8 Executive Committee designated universities to focus on M8 Action Initiatives (M8-AIs) in particular areas in which each university has strengths and expertise and would be interested in leading an M8 network. Our proposal on Neglected Tropical Diseases was accepted and will be led by Prof. Aluisio Segurado, current President of the International Committee.

All these actions were implemented due to the dedication of our professors, Students and colleagues who have played an important role in acting as ambassadors for the Faculty and in developing and fostering international awareness of our activities.

\section{Our Aspiration}

FMUSP aspiration is to increase our International reputation and become one of the first choice in the minds of students, professors and researchers around the world. This aspiration improves our quality in learning and transferring research and knowledge. We intend to develop further our relationships with the best international universities and with our partners in order to increase our exchange programs.

Enhancing our international reputation should create 
a virtuous circle, building further and bigger opportunities for international research partnerships with other worldclass universities and institutions worldwide; improving our ability to shape and secure increased levels of international research funding; attracting the best minds to work with us; increasing our ability to secure sustainable income flows through offering increased opportunities to international students to study here; and offering all of our students increased international experience and understanding that will support them in building a better future in an interdependent world.

Becoming one of the first choice is a hard task and a process, not an end-state, and will require continuous improvement in our activities. Measuring success internationally through the perceptions of others means that we will focus on how we are seen by all the outstanding people working in the area. Continuously we will ask ourselves how we can best demonstrate the high demand of our expectations.

\section{Key Actions}

To achieve our ambitions, the following priorities can be identified:

- Provide accessible information about our international activity and what we offer;

- Offer a learning and living experience that explicitly meets the needs and expectations of international as well as domestic students;

- Best prepare our students to thrive in and contribute to an increasingly interdependent world;

- Continue to develop a strong international focus and awareness in all our staff and in all that we do;

- Focus on building strategic partnerships in a focused number of countries or regions;

- Report annually on our progress.

\section{Concluding Remarks}

The aspiration and implementation of an international strategic plan is necessarily broad and included a wide range of activities within FMUSP. It will need to be refined from what we learn along with the development of our agenda, always taking into account the inevitable fast-changing external context. The success is dependent on the energy, collaboration and outward-looking attitude of all FMUSP members. Given the necessary support and total engagement, building on our existing international strengths and connections, we will achieve our aspiration to become one of the first choice in the minds of students, professors, researchers and staff willing to live an effective international experience. 